\title{
EVALUATION OF THE FACTORS AFFECTING THE LENGTH OF STAY IN HOSPITAL OF TRANSCATHETER AORTIC VALVE IMPLANTATION (TAVI) CASES
}

\author{
Sibel Buyukcoban ${ }^{1}$, Leyla lyilikci ${ }^{2}$
}

${ }^{1}$ Dokuz Eylul Universty Faculty of Medicine Department of Anesthesiology, İzmir, Turkey

${ }^{2}$ Dokuz Eylul University Faculty of Medicine, Department of Anesthesiology and Reanimation, İzmir, Turkey

Address for Correspondence: Sibel Buyukcoban, MD, E-mail: sibelbuyukcoban@yahoo.com

Received: 10.01.2021; Accepted: 08.02.2021; Available Online Date: 04.03.2021

(C) Copyright 2021 by Dokuz Eylul University, Institute of Health Sciences - Available online at https://dergipark.org.tr/en/pub/jbachs

Cite this article as: Buyukcoban S, Iyilikci L. Re-Visited ; Evaluation Of The Factors Affecting The Length Of Hospital Stay İn Tavı (Transcatheter Aortic Valve Implantation) Cases J Basic Clin Health Sci 2021; 1: 22- 29.

\begin{abstract}
Purpose: In the treatment of inoperable patients with severe aortic stenosis or at high surgical risk, transcatheter aortic valve implantation (TAVI) is applied as an alternative to surgical aortic valve replacement. In our study, it was aimed to evaluate the factors affecting the length of stay in hospital of TAVI cases.

Method: After obtaining the approval of the ethics committee, the patients who received TAVI between 09.06.2012-19.01.2018 in the Interventional Cardiology unit of Dokuz Eylül University were retrospectively screened. A total of 243 patients were included in the study. Demographic data, preoperative accompanying diseases and echocardiographic results of the cases, the type of anesthesia applied, the duration of postoperative coronary intensive care and hospital stay of them were recorded. The analysis of the data was carried out in the SPSS 22.0 statistical package program, and the independent variables and their relationship with discharge were tested with chi-square analysis.

Results: $53.5 \%$ of the patients who underwent transcatheter aortic valve implantation received general anesthesia, $46.5 \%$ received local anesthesia and sedation. $93.8 \%$ of the patients were discharged upon recovery. There was no significant difference between patients' gender, age, mitral insufficiency level, aortic insufficiency level, tricuspid insufficiency level, aortic valve area, and preoperative comorbid diseases and postoperative discharge time $(p>0.05)$. There was a significant difference between the postoperative length of stay in hospital and the type of anesthesia $(p=0.008)$. It was shown that patients underwent general anesthesia were discharged later than patients underwent sedation.

Conclusion: Due to the high risks of surgery, it is of vital importance to shorten the length of stay in hospital in high-risk patients over 65 years of age who undergo TAVI.
\end{abstract}

Keywords: TAVI, sedation, general anaesthesia, length of stay in hospital

\section{INTRODUCTION}

According to the population projections made by the Ministry of Health in 1996, it is estimated that the population aged 65 and over will be $12.1 \%$ in our country in 2030 (1). In the geriatric age group, systems work in balance under physiological conditions, with reduced organ and reserve capacity. Atrophic and fibrotic changes in the aging process also affect the aortic valve. Aortic stenosis (AS) is the most common valvular heart disease in adults over 65 (2). Moderate 
or severe aortic stenosis affects $13.3 \%$ of adults over the age of 75 (3). The annual mortality rate among patients with symptomatic severe AS is $25 \%$, and it demonstrates an average of 3 years of survival if not intervened. Aortic valve replacement is treated with cardiopulmonary bypass in symptomatic patients, which requires thoracotomy (4). Cardiopulmonary bypass operation has high mortality rates $(4-18 \%)$, especially in elderly patients with AS with comorbid diseases (5). The TAVI method has emerged as an alternative to surgical aortic valve replacement in treating inoperable patients with severe aortic stenosis or high surgical risk (6-9). TAVI is a revolutionary practice in the management of Serious AS. It is predicted that the number of patients who will benefit from TAVI will increase 4-10 times with the expanding elderly population in the future (18). TAVI (10), which was first performed in 2002, is recommended as a less invasive intervention for severe AS patients who cannot be operated on (11). TAVI is a safe and effective treatment in treating severe AS patients with high surgical risk (12). The definition of severe AS is either aortic valve area less than $1 \mathrm{~cm} 2$ in echocardiography or aortic valve pressure gradient higher than $40 \mathrm{mmHg}$ in echocardiography (13). Besides, $30 \%$ of patients with symptomatic severe aortic stenosis cannot have aortic valve replacement due to advanced age and accompanying diseases, and their quality of life reduces. If severe AS is not treated, it is associated with up to $50 \%$ mortality in 1 year $(14,15)$.

Recent changes in TAVI practice, such as conscious sedation without general anesthesia, accelerated recovery, early discharge, and low complication rates, will likely increase its cost-effectiveness (19). During the TAVI application, the anesthesiologist closely follows the patient from the preoperative period to discharge. All anesthesia guidelines recommend postponing major elective noncardiac surgery without correction of the AS by surgical or percutaneous interventions. During the TAVI application, the anesthesiologist closely follows the patient from the preoperative period to discharge. All anesthesia guidelines recommend that major elective noncardiac surgery be delayed until surgical or percutaneous interventions correct the ED. Otherwise, patients are at high risk of perioperative heart failure or myocardial infarction; therefore, anesthetic management is difficult $(20,21)$. In this study, each patient's condition before the intervention is discussed by the council formed by cardiologists, cardiovascular surgeons, and anesthesiologists, and the suitability of the TAVI case is evaluated, and then the indication for TAVI is decided. This study evaluates the factors affecting the length of hospital stay in transcatheter aortic valve implantation cases.

\section{METHODS}

After the ethics committee's approval, 511 patients who underwent transcatheter aortic valve implantation in the Dokuz Eylül University Interventional Cardiology unit between 09.06.2012-19.01.2018 were retrospectively screened. Since the survival data were taken for two years, the cases after 19.01.2018 were excluded from the study. Age, gender, comorbidities, aortic valve maximal pressure gradient, LVEF (preTAVI ejection fraction), preTAVI pulmonary arterial pressure, TAVI procedure date, postoperative intensive care stay and postoperative hospital stay were recorded. Patients who stayed in the hospital for $<3$ days after the operation were classified as "early discharge" as the postoperative stay period, and those with a postoperative stay of $>3$ days were classified as "late discharge" (22-24). Cases in which $90 \%$ of the data could not be reached were excluded from the study (25 patients); 243 patients were included. These applications were performed in the interventional cardiology unit, standard monitoring, and anesthesia device recommended by the ASA (American Society of Anesthesiologist). The cases were monitored by heart rhythm, invasive arterial pressure, end-tidal $\mathrm{CO} 2$ and ECG, urine output, and temperature monitoring.

The intervention was accompanied by an anesthesiologist, an anesthesia assistant, and an anesthesia technician. Thiopental $(4-7 \mathrm{mg} / \mathrm{kg})$ and fentanyl $(1-2 \mathrm{mcg} / \mathrm{kg})$ rocuronium $(0.5 \mathrm{mg} / \mathrm{kg})$ are given to patients who are decided to undergo general anesthesia (GA), and the intervention is maintained with sevoflurane $(2 \%)$ after being intubated. Fentanyl $(1-2 \mathrm{mcg} / \mathrm{kg})$ and midazolam $(0.05 \mathrm{mg} / \mathrm{kg})$ were used in patients who preferred local anesthesia and sedation (LAS), Propofol (1-1.5mg/kg) and midazolam were repeated when necessary, and the procedure was completed. Preparation was made as if all patients would be given general anesthesia. GA was used when respiratory depression, neurological problems, hemodynamic instability, or severe surgical complications were experienced during local anesthesia. Noradrenaline infusion was readily available, and it was used to provide hemodynamic 
stabilization when needed (5). The cardiovascular surgery team waited, ready to intervene when needed. Before the TAVI procedure, a temporary pacemaker was placed in each patient; after the procedure was completed with fluoroscopy, femoral angiography was performed, and it was confirmed that there was no vascular damage. The anesthesiologist extubated patients who received general anesthesia if their conditions were appropriate or intubated them to the coronary intensive care unit. At the end of the procedure, the temporary pacemaker was removed if unnecessary. According to his general condition, the patient, who was followed up for at least 4 hours in intensive care, was transferred to the service, postoperative follow-up was completed, and discharged.

The data analysis was carried out in the SPSS 22.0 statistical package program, and the relationships between independent variables and discharge were tested with chi-square analysis. The 'student $t$ ' test was used to evaluate the relationship between the anesthesia type of TAVI cases and the duration of postoperative intensive care and hospital stay.

\section{RESULTS}

$95 \%$ of the cases were 65 years and older, and the mean age was calculated as $78.25 \pm 8.24$ (47-93). $53.5 \%$ of the patients undergoing TAVI had GA, and $46.5 \%$ had LAS.

While $93.8 \%$ of 243 patients were discharged with cure; 2 patients were sent to palliative care and died within six months. When we included these patients, $6.2 \%$ of the cases were exitus without being discharged from the hospital. Of the 13 fatal cases, eight died in the first three days, and four of them died within the first 24 hours. While $3.2 \%$ of the cases $(n=8)$ died before 30 days, $47.7 \% \quad(n=116)$ survived more than 30 days, less than two years, $46 \% \quad(n=112)$ survived more than two years.

While the average duration of patients' stay in the postoperative coronary intensive care unit is $3,6 \pm 4,05$ days, the postoperative hospital stay is $7,85 \pm 6,10$ days. $19.4 \%$ of the patients (47 people) stayed in the hospital for three days or less postoperatively and were discharged early.

No significant difference was observed in terms of postoperative hospital stay in terms of gender, age, mitral insufficiency level, aortic insufficiency level, tricuspid insufficiency level, aortic valve area, and accompanying diseases. However, a significant difference was found with the type of anesthesia. It was found that patients who underwent GA were discharged later than those who received LAS (Table 1).

No significant difference was found between the type of anesthesia and gender, age, mitral regurgitation level, aortic insufficiency level, tricuspid insufficiency level, aortic valve area (AVA), transaortic gradient, postoperative intensive care period, and discharge type. A significant difference was found between GA and LAS between ASA classification and previous cerebrovascular event (CVE). More sedation was applied to ASA II patients $(p=0.001)$. Although the number of CVOs was low, GA was used more in patients with a history of CVO $(p=0.044)$. It was found that patients who underwent $A$ were discharged later than those who received LAS and stayed longer in the intensive care unit (Table 2).

\section{DISCUSSION}

TAVI operation is an attempt that the anesthesia team performs very carefully. Although TAVI is applied to an increasing number of geriatric patients, there is still no consensus on TAVI's anesthetic management (26). The postoperative discharge time is an important indicator and the success of the intervention in geriatric patient anesthesia management (26). It has been found that the prolongation of the hospital stay of geriatric patients is an independent risk factor for mortality (27).

In our study, $46 \%$ of the patients whose mean age was $78.25 \pm 8.24$ when TAVI was applied lived more than two years after the intervention. When the literature was examined, it was observed that the mean age was $82.6 \pm 1.2$ in the study of Motloch et al. (29), while the mean age of 125 consecutive cases in the study of Dehedin et al. (30) was 83 (78-87) and $11.2 \%$ lived more than a year. $6.2 \%$ of 243 cases in our center and $8 \%$ of 125 cases of Dehedin et al. (30) died before they could be discharged from the hospital.

In our study, by the study of Motloch LJ (29) et al., no relationship was found between the gender, preoperative diabetes mellitus, chronic obstructive pulmonary disease, hypertension, underwent coronary bypass surgery, preoperative valve 
insufficiency, and postoperative discharge time of the cases $95 \%$ of which were geriatric (over 65 years old). There was no relationship between the discharge upon recovery rates of the patients with the type of anesthesia. However, a significant difference was found regarding the type of anesthesia chosen. From the literature, it has been shown that patients who underwent GA were discharged later than those who underwent LAS $(29,30)$.
In our results, the length of stay in the hospital was $6.30 \pm 4.74$ days in patients who underwent LAS and $9.19 \pm 6.81$ days in patients who underwent GA, but in the study of Deheni et al. (30), the length of stay in hospital was $8.8 \pm 0.9$ days in patients who underwent LAS, and $11.9 \pm 1.9$ days in patients who underwent GA.

Table 1. Distribution of characteristics of TAVI cases according to postoperative hospital stay

\begin{tabular}{|c|c|c|c|c|c|}
\hline & \multicolumn{2}{|c|}{ Early discharge } & \multicolumn{2}{|c|}{ Late discharge } & \multirow[t]{2}{*}{ p value } \\
\hline & $\mathrm{N}$ & $\%^{*}$ & $\mathrm{~N}$ & $\%{ }^{*}$ & \\
\hline $\begin{array}{c}\text { Sex } \\
\text { Female } \\
\text { Male }\end{array}$ & $\begin{array}{l}26 \\
21\end{array}$ & $\begin{array}{l}19,3 \\
19,8\end{array}$ & $\begin{array}{c}109 \\
85\end{array}$ & $\begin{array}{l}80,2 \\
80,2\end{array}$ & 0,914 \\
\hline $\begin{array}{c}\text { Preoperative Al } \\
\text { None } \\
\text { Mild } \\
\text { Moderate } \\
\text { Severe }\end{array}$ & $\begin{array}{c}18 \\
19 \\
8 \\
2\end{array}$ & $\begin{array}{l}20,7 \\
25,0 \\
12,7 \\
13,3\end{array}$ & $\begin{array}{l}69 \\
57 \\
55 \\
13\end{array}$ & $\begin{array}{l}79,3 \\
75,0 \\
87,3 \\
86,7\end{array}$ & 0,288 \\
\hline $\begin{array}{c}\text { Preoperative Ml } \\
\text { None } \\
\text { Mild } \\
\text { Moderate } \\
\text { Severe }\end{array}$ & $\begin{array}{c}9 \\
17 \\
16 \\
5\end{array}$ & $\begin{array}{l}18,4 \\
21,8 \\
18,8 \\
17,2\end{array}$ & $\begin{array}{l}40 \\
61 \\
69 \\
24\end{array}$ & $\begin{array}{l}81,6 \\
78,2 \\
81,2 \\
82,8\end{array}$ & 0,936 \\
\hline $\begin{array}{c}\text { Preoperative TI } \\
\text { None } \\
\text { Mild } \\
\text { Moderate } \\
\text { Severe }\end{array}$ & $\begin{array}{c}21 \\
12 \\
11 \\
3\end{array}$ & $\begin{array}{c}26,6 \\
20,3 \\
15,9 \\
8,8\end{array}$ & $\begin{array}{l}58 \\
47 \\
58 \\
31\end{array}$ & $\begin{array}{l}73,4 \\
79,7 \\
84,1 \\
91,2\end{array}$ & 0,134 \\
\hline $\begin{array}{c}\text { Comorbidities } \\
\text { DM } \\
\text { COPD } \\
\text { HT } \\
\text { CABG (underwent) } \\
\text { CVA }\end{array}$ & $\begin{array}{c}12 \\
6 \\
27 \\
6 \\
2\end{array}$ & $\begin{array}{l}22,2 \\
14,3 \\
20,9 \\
22,2 \\
22,2\end{array}$ & $\begin{array}{c}42 \\
36 \\
102 \\
21 \\
7\end{array}$ & $\begin{array}{l}77,8 \\
85,7 \\
78,1 \\
77,8 \\
77,8\end{array}$ & $\begin{array}{l}0,567 \\
0,618 \\
0,548 \\
0,705 \\
0,834\end{array}$ \\
\hline & \multicolumn{2}{|c|}{ mean $\pm S D$} & \multicolumn{2}{|c|}{ mean $\pm S D$} & $p$ value \\
\hline Age & \multicolumn{2}{|c|}{$77,40 \pm 8,15$} & \multicolumn{2}{|c|}{$78,48 \pm 8,31$} & 0,427 \\
\hline AVA & \multicolumn{2}{|c|}{$0,64 \pm 0,16$} & \multicolumn{2}{|c|}{$0,63 \pm 0,17$} & 0,646 \\
\hline Number of patients & 47 & $19,5^{* *}$ & 194 & $80,5^{* *}$ & \\
\hline
\end{tabular}

${ }^{*}$ Column percentage ${ }^{* *}$ Row percentage ${ }^{\#}$ Chi-square analysis ${ }^{\# \#}$ Student $t$ test

Transcatheter aortic valve implantation (TAVI), American Society of Anesthesiologists (ASA), Aortic valve insufficiency (AI), mitral insufficiency (MI), tricuspid insufficiency (TI), general anesthesia (GA), local anesthesia sedation (LAS), Diabetes Mellitus (DM), Chronic obstructive pulmonary disease (COPD), Hypertension (HT), Coronary artery bypass graft (CABG), cerebrovascular accident (CVA), standard deviation (SD). 
Table 2.Distribution of patients according to the type of anesthesia applied.

\begin{tabular}{|c|c|c|c|c|c|}
\hline & \multicolumn{2}{|l|}{ GA group } & \multicolumn{2}{|c|}{ LAS group } & \multirow[t]{2}{*}{ p value ${ }^{\#}$} \\
\hline & $\mathrm{N}$ & $\%^{*}$ & $\mathrm{~N}$ & $\%^{*}$ & \\
\hline $\begin{array}{l}\text { Male } \\
\text { Female }\end{array}$ & $\begin{array}{l}59 \\
71\end{array}$ & $\begin{array}{l}45,4 \\
54,6\end{array}$ & $\begin{array}{l}48 \\
65\end{array}$ & $\begin{array}{l}42,4 \\
57,5\end{array}$ & 0,698 \\
\hline $\begin{array}{l}\text { ASAll } \\
\text { ASAIII }\end{array}$ & $\begin{array}{l}80 \\
50\end{array}$ & $\begin{array}{l}46,2 \\
71,4\end{array}$ & $\begin{array}{l}93 \\
20\end{array}$ & $\begin{array}{l}53,8 \\
28,6\end{array}$ & 0,001 \\
\hline $\begin{array}{c}\text { Comorbidities } \\
\text { DM } \\
\text { HT } \\
\text { CABG (underwent) } \\
\text { CVA } \\
\text { COPD }\end{array}$ & $\begin{array}{l}29 / 130 \\
59 / 130 \\
13 / 130 \\
5 / 130 \\
19 / 130\end{array}$ & $\begin{array}{l}22,3 \\
45,4 \\
10,0 \\
3,9 \\
14,6\end{array}$ & $\begin{array}{l}26 / 113 \\
70 / 113 \\
14 / 113 \\
4 / 113 \\
23 / 113\end{array}$ & $\begin{array}{l}23,0 \\
61,9 \\
12,4 \\
3,5 \\
20,4\end{array}$ & $\begin{array}{l}0,567 \\
0,548 \\
0,705 \\
0,044 \\
0,618\end{array}$ \\
\hline $\begin{array}{l}\text { Preoperative Al } \\
\text { None } \\
\text { Mild } \\
\text { Moderate } \\
\text { Severe }\end{array}$ & $\begin{array}{l}49 \\
44 \\
28 \\
9\end{array}$ & $\begin{array}{l}55,6 \\
57,8 \\
43,7 \\
60\end{array}$ & $\begin{array}{l}39 \\
32 \\
36 \\
6\end{array}$ & $\begin{array}{l}44,4 \\
42,2 \\
36,3 \\
40\end{array}$ & 0,326 \\
\hline $\begin{array}{l}\text { Preoperative Ml } \\
\text { None } \\
\text { Mild } \\
\text { Moderate } \\
\text { Severe }\end{array}$ & $\begin{array}{l}31 \\
38 \\
42 \\
19\end{array}$ & $\begin{array}{l}63,2 \\
48,1 \\
49 \\
65\end{array}$ & $\begin{array}{l}18 \\
41 \\
44 \\
10\end{array}$ & $\begin{array}{l}36,8 \\
51,9 \\
51 \\
35\end{array}$ & 0,155 \\
\hline $\begin{array}{c}\text { Preoperative TI } \\
\text { None } \\
\text { Mild } \\
\text { Moderate } \\
\text { Severe }\end{array}$ & $\begin{array}{l}45 \\
31 \\
33 \\
21\end{array}$ & $\begin{array}{l}57 \\
51 \\
47 \\
63\end{array}$ & $\begin{array}{l}34 \\
30 \\
36 \\
13\end{array}$ & $\begin{array}{l}43 \\
49 \\
53 \\
37\end{array}$ & 0,497 \\
\hline & mean $\pm S D$ & & mean $\pm S$ & & $p$ value \\
\hline $\begin{array}{l}\text { Postoperative coronary intensive care } \\
\text { stay (days) }\end{array}$ & $5,13 \pm 0,45$ & & $2,20 \pm 0$ & & 0,0001 \\
\hline Postoperative hospital stay (days) & $9,19 \pm 6,81$ & & $6,30 \pm 4$ & & 0,0000 \\
\hline Total & 130 & $53.4^{\star \star}$ & 113 & $46.6^{\star \star}$ & \\
\hline
\end{tabular}

${ }^{*}$ Column percentage ${ }^{* *}$ Row percentage \# Chi-square analysis ${ }^{\# \#}$ Student $t$ test

General anesthesia (GA), Local anesthesia sedation (LAS), ASA, Diabetes mellitus (DM), hypertension (HT), coronary artery bypass graft (CABG), Cerebrovascular accident (CVA), Chronic obstructive pulmonary disease (COPD), Aortic valve insufficiency (AI), Mitral insufficiency (MY), tricuspid insufficiency (TI), Standard deviation (SD). 
The anesthesiologist's goal should be to provide less invasive anesthesia/analgesia without compromising the patient's safety or comfort. Local anesthesia plus sedation is a reliable alternative to general anesthesia. General anesthesia is associated with good hemodynamic stability, cardioprotective properties, adequate attenuation of the stress response, and early awakening. However, general anesthesia use is closely related to the learning curve of the operator (31).

Besides, patients who undergo TAVI with LAS can be mobilized significantly earlier than the GA group. In general, early mobilization in patients undergoing vascular or cardiac surgery results in decreased postoperative mortality, decreased postoperative complications, and shorter intensive care unit and hospital stay (32). Moloch LJ et al. (29) also found a tendency towards shorter intensive care and hospital stays in the LAS group, consistent with our study results.

The LAS combination also has advantages such as early detection of neurological complications, short procedure time, rapid recovery, and reducing the need for postoperative care (33).

Our study's results support LAS application in possible conditions to shorten the hospital stay of TAVI operations. In anesthesia, individualized preoperative care and perioperative management of each patient is a prerequisite. However, a road map enlightened with literature information will help anesthesiologists make sudden decisions such as cardiac interventions.

We believe that our study will guide our colleagues who will choose in TAVI application and shed light on the fact that high-risk geriatric patients will shorten the length of hospital stay. Anaesthesiologists should play a participatory role in developing care standards for these high-risk patients and support continuous improvement towards a more minimally invasive approach.

Acknowledgement: We are grateful to the interventional cardiology unit for nurses, technicians and doctors for their involvement in the study. We are grateful support Prof. Dr. A. Oktay Ergene ve Uzman Dr. Tuba Ekin.

Funding: No institutional departmental funds were received in the conduct of the study.

Conflict of interest: Authors have not disclosed any potential conflicts of interest.

Peer-review: Externally peer-reviewed.

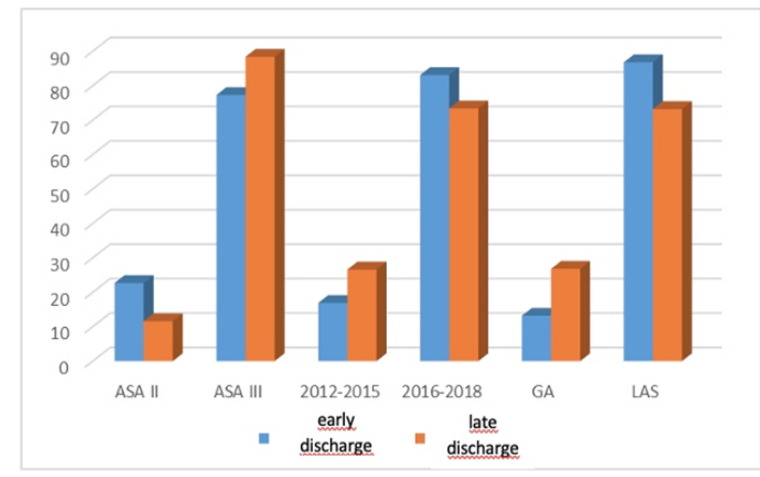

Figure 1. Distribution of TAVI cases by postoperative hospital stay by ASA, intervention year, and anesthesia type

American Society of Anesthesiologists (ASA), General anesthesia (GA), Local anesthesia sedation (LAS), early discharge (less than three postoperative hospital stay), late discharge (more than three postoperative hospital stay)

\section{REFERENCES}

1. Bahar A., Parlar S, Yaşııık ve Evde Bakım. Fırat sağlık Hizmetleri Dergisi, 2007; 2(4):32-39.

2. E.R. Bates. Treatment options in severe aortic stenosis.Circulation, 124;2011:355-59.

3. V.T. Nkomo, J.M.Gardin , T.N. Skelton, J.S. Gottdiener, C.G. Scott, Enriquez-Sarrono. Burden of valvular heart diseases:a population based study. Lancet,368;2006:1005-11

4. Vymazal T. Minimally invasive approach to calcified aortic valve replacement: Anaesthetic considerations. Indi Indian J Anaesth 2015;59:338-41.

5. Covello RD, Ruggeri L, Landoni G, Guarracino F, Bignami E, Gonfalini M, et al. Transcatheter implantation of an aortic valve: anesthesiological management. Minerva Anestesiol 2010;76:100-8.

6. Vahanian A, Alfieri $\mathrm{O}, \mathrm{Al}-\mathrm{Attar} \mathrm{N}$ et al. Transcatheter valve implantation for patients with aortic stenosis: a position statement from the European Association of Cardio-Thoracic Surgery (EACTS), the European Society of Cardiology (ESC), in collaboration with the European Association of Percutaneous Cardiovascular Interventions (EAPCI). Eur Heart J 2008;29:14631470(crossref)

7. Lung B, Baron G, Butchart EG, Delahaye F, Gohlke-Barwolf C, Levang OW, Tornos P, Vanoverschelde JL, Vermeer F, Boersma E, Ravaud P, Vahanian A (2003) A prospective 
survey of patients with valvular heart disease in Europe: the Euro Heart Survey on Valvular Heart Disease. Eur Heart J 24:1231-1243 (crossref)

8. Lung B, Cachier A, Baron $G$ et al Decisionmaking in elderly patients with severe aortic stenosis: why are so many denied surgery? Eur Heart J 2005;26:2714-2720(crossref)

9. Conradi L, Seiffert M, Franzen O, Baldus S, Schirmer J, Meinertz T, Reichenspurner $\mathrm{H}$, Treede H (2011) First experience with transcatheter aortic valve implantation, concomitant percutaneous coronary intervention. Clin Res Cardiol 100:311-316(crossref)

10. Cribier A, Eltchaninoff $H$, Bash $A$ et al. Percutaneous transcatheter implantation of an aortic valve prosthesis for calcific aortic stenosis: first human case descrip- tion. Circulation 2002; 106: 3006-8. )

11. Rex S. Anesthesia for transcatheter aortic valve implantation: an update. Curr Opin Anaesthesiol 2013;26:456-66. [CrossRef ]

12. Petronio AS, Giannini C, De Carlo M, Bedogni F, Colombo A, Tamburino C, et al. Anaesthetic management of transcatheter aortic valve implantation: results from the Italian CoreValve registry. Eurolntervention 2016;12:381-8. [CrossRef ]

13. Chou WH, Wang YC, Huang HH, Cheng HL, Lin YS, Wang MJ, et al. Transcatheter aortic valve implantation: Anesthetic experience of retrograde transfemoral approach with CoreValve ReValving System. Acta Anaesthesiol Taiwan 2014;52:2-5. [CrossRef ]

14. Bonow RO, Leon MB, Doshi D, Moat N. Management strategies and futurechallenges for aortic valve disease. Lancet (London, England). 2016;387(10025):1312-23.2.

15. Leon MB, Smith CR, Mack M, Miller DC, Moses JW, Svensson LG, Tuzcu EM,Webb JG, Fontana GP, Makkar RR, et al. Transcatheter aorticvalveimplantation for aortic stenosis in patients who cannot undergo surgery. NEngl $\mathrm{J}$ Med. 2010;363(17):1597-607.

16. He W., Goodkind D., Kowal P.: An aging world.2015. Washington, DC. January 3, 2019

17. Wohlgemut J.M., Ramsay G., Jansen J.O.: The changing face of emergency general surgery.Ann Surg 2018

18. Frohlich GM, Baxter PD, Malkin CJ, Scott DJ, Moat NE, Hildick-Smith $D$ et al . Comparative survival after transapical, direct aortic, and subclavian transcatheter aortic valve implantation (data from the Uk TAVI registry). Am J Cardiol 2015; 116: 1555- 9 .

19. Contemporary review of severe aortic stenosis.Adams HSL, Ashokkumar S, Newcomb A, Maclsaac Al, Whitbourn RJ, Palmer S.Intern Med J. 2019 Mar;49(3):297-305. doi: 10.1111/imj.14071.PMID: 30091235 Review

20. Erdost Aksu H, İyilikçi L, Duru SL et al. Experiences of transcatheter aortic valve Implantation with sevre aortic stenosis. Haydarpasa Numune Med J 2020;60(29173-77.

21. Agarwal, A. Rajamanickam, N.S. Bajaj, et al.Impact of aortic stenosis on postoperative outcomes after noncardiac surgeries.Circ Cardiovasc Qual Outcomes, 6 (2013), pp. 193200

22. Tashiro, S.V. Pislaru, J.M. Blustin, et al.Perioperative risk of major non-cardiac surgery in patients with severe aortic stenosis: a reappraisal in contemporary practiceEur Heart $\mathrm{J}$, 35 (2014), pp. 2372-2381

23. Mallikethi-Reddy S,Akitonye E,Telila $T$ et al. transcaatheter aortic valve implantation in the United States: Predictors of early hospital discharge.J Interven Cardiol.2017;30;149-55.

24. Barbanti M, Capranzano P, Ohno Y, et al. Early discharge after transfemoral transcatheter aortic valve implantation. Heart. 2015;101:1485-1490.

25. Durand E, Eltchaninoff $H$, Canville $A$, et al. Feasibility and safety of early discharge after transfemoral transcatheter aortic valve implantation with the Edwards SAPIEN-XT prosthesis. Am J Cardiol. 2015;115:1116-1122.

26. Ruggeri L, Gerli C, Franco A, Barile L, Magnano di San Lio MS, Villari $N$, et al. Anesthetic management for percutaneous aortic valve implantation: an overview of worldwide experiences. HSR Proc Intensive Care Cardiovasc Anesth 2012;4:40-6.

27. Shaw E,Gornila A,Piriz $M$ et al.Multistate modelling to estimate excess length of stay and risk of death associated with organ/space infection after elective colorectal surgery. Journal of Hospital Infection.2018;100(4):400-05.

28. Pardo PL,Garcia S,Cortes JJB. Influence of the length of hospital stay mortality after discharge in older patients with acute medical diseases. Gac Sanit. 2016;30(5):375-8. Motloch LJ, Rottlaender D, Reda S. Et all. Local versus general anesthesia 
for transfemoral aortic valve implantation Clinical Research in Cardiology.2012;101:45-53.

29. Dehedin B, Guinot PG, Ibrahim H et al.Aneshesia and perioperative management of patients who undergo transfemoral transcatheter aortic valve implantation: an observational study of general versuslocal/regional anesthesia in 125 consecutive patients. J Cardiothroc Vasc Anesth. 2011;(6):1036-43.

30. Franco A, Gerli C, Ruggeri L, Monaco F. Anesthetic management of transcatheter aortic valve implantation. Annals of Cardiac Anaesthesia 2012;15:54-63.

31. O'Connor ED, Walsham J (2009) Should we mobilise critically ill patients? A review. Crit Care Resusc 2009;11:290-300

32. Melidi E, Latsios G, Toutouzas K, Vavouranaki M, Tolios I, Gouliami M, et al. Cardio-anesthesiology considerations for the transcatheter aortic valve implantation (TAVI) procedure. Hellenic Society of Cardiyology 2016;57:401-6. 